\title{
Comparative Study between Hemorrhoidectomy with Harmonic Scalpel Versus Electrocautery
}

\author{
AHMED E. MORAD, M.D.*; ADEL M. ABDULLAH, M.D.**; KAREEM A. KAMEL, M.D.* and \\ REEM S.M.M. ABUELANIN, M.Sc.** \\ The Department of General Surgery, Faculties of Medicine, Ain Shams* and 6 th of October** Universities
}

\begin{abstract}
Background: Hemorrhoidal disease is a very prevalent disorder that arises from engorgement of internal and/or external vascular plexuses surrounding the anal canal. Hemorrhoidectomy is the standard treatment for grade III or grade IV internal hemorrhoids; in spite of this, pain after conventional hemorrhoidectomy is still a major challenge.
\end{abstract}

Aim of Study: To compare the outcome of hemorrhoidectomy using Harmonic scalpel without ligation of the pedicle versus electrocautery with ligation of the pedicle as regarding cost, operative time, post-operative bleeding, pain, and healing process.

Patients and Methods: This study was a prospective, clinical, randomized, trial that included 50 patients grade III internal hemorrhoids with external components or grade IV disease. The patients were divided into two groups: Group I that included 25 patients underwent electrocautery with ligation of the pedicle and Group II which included 25 patients underwent Harmonic scalpel hemorrhoidectomy without ligation of the pedicle.

Results: There was statistically significant association between type of procedure and operative time $(p=0.001)$ Patients who underwent Harmonic scalpel hemorrhoidectomy had statistically significant lower pain score at day $1,3,7$, 15 , and 30 . There was statistically significant association between type of procedure and time to heal $(p=0.001)$. Patients who underwent Harmonic scalpel hemorrhoidectomy had statistically significant shorter time to complete healing. On the contrary, there was statistically significant association between type of procedure and hospital stay $(p=0.18)$. There was statistically significant association between type of procedure and late complications $(p=0.001)$. Patients who underwent Harmonic scalpel hemorrhoidectomy had statistically significant less incidence of late complications.

Conclusion: It is concluded that there was significantly reduced post-operative pain after Harmonic Scalpel hemorrhoidectomy compared with electrocautery controls. The diminished post-operative pain in the Harmonic Scalpel group likely results from the avoidance of lateral thermal injury.

Correspondence to: Dr. Reem S.M.M. Abuelanin, E-Mail: reem.s.mohammed@ hotmail.com
Key Words: Hemorrhoidectomy - Harmonic Scalpel - Electrocautery-Post-operative pain.

\section{Introduction}

HEMORRHOIDS are normal anatomic clusters of vascular tissue, smooth muscle, and connective tissue that lie along the anal canal in 3 columns, forming the anal cushions; they lie in left lateral, right anterior, and right posterior positions [1] Hemorrhoids occur when the supporting connective tissues of the anal cushions deteriorate and slides downward, causing venous dilatation and the overlying mucosa becomes thin and friable leading to painless bright bleeding per rectum. Hemorrhoids are classified to external or internal. External hemorrhoids develop distal to the dentate line and are usually associated with pain while internal hemorrhoids develop proximal to the dentate line and are typically painless [2]

Depending on the severity, they are classified into grades (3): Grade I: Prominent hemorrhoidal vessels, no prolapse. Grade II: Prolapsed hemorrhoids with Valsava maneuver; spontaneously reduces. Grade III: Prolapsed hemorrhoids with Valsava maneuver; manual reduction is required. Grade IV: Chronically prolapsed hemorrhoids; manual reduction is ineffective.

Most believe that hemorrhoids are caused by chronic constipation, prolonged sitting, and vigorous straining, some other potential etiologies are: Straining and constipation [4], pregnancy, decrease venous return, portal hypertension and anorectal varices [5]

Guidelines according to American college of gastroenterology (ACG) and American society of colon and rectal surgeons (ASCRS): They recommend that patients with symptomatic hemorrhoids 
initially be treated with increased fiber and adequate fluid intake [6] and counseling regarding defecation habits [3].

The ACG guidelines also recommend that if dietary modifications do not eliminate symptoms in patients with first-to third-degree hemorrhoids, various office procedures, including banding, sclerotherapy, and infrared coagulation, should be considered, with ligation probably being the most effective treatment.

The ACG further states that patients should be referred for surgery if they are refractory to or unable to tolerate office procedures, if their hemorrhoids are accompanied by large symptomatic external tags, or if they have either fourth-degree or large third-degree hemorrhoids [6].

\section{Surgical treatment for grade III and IV hemor- rhoids:}

The most effective hemorrhoidectomy methods done are the Milligan-Morgan open hemorrhoidectomy [7] and the Ferguson closed hemorrhoidectomy [8]. Although, they may be the most effective treatment for hemorrhoids, complications, such as post-operative bleeding, surgical-site anal pain, soaking, delayed healing, and anal stenosis can occur post-operatively.

As a result, various surgical equipment, surgical methods, and supportive therapies have been introduced to overcome the post-operative complications.

Surgical excision using Harmonic Scalpel is a modern technique used for ablation of symptomatic third degree and all fourth-degree hemorrhoids. Compared with electrocautery, Harmonic Scalpel causes minimal lateral thermal injury during tissue dissection [9]. The resulting mucosal defect in this study is left open.

The use of Harmonic scalpel in hemorrhoidectomy is relatively the low temperature that divides tissues through the high frequency ultrasonic energy that disrupts protein hydrogen bonds. The relatively low temperature $\left(80^{\circ} \mathrm{C}\right)$ yielded results in minimal lateral thermal injury $(<1.5 \mathrm{~mm})$ [10] .

On the contrary, electrocautery causes significant lateral thermal injury and burn several millimeters in depth [11]. This difference causes less postoperative pain and decreases the need for analgesics [9]. In our study we present our experience in using Harmonic scalpel in hemorrhoidectomy and evaluating the post-operative complications in comparison to the use of electrocautery.
Aim of the study:

The aim of this study is to compare the outcome of hemorrhoidectomy using Harmonic scalpel without ligation of the pedicle versus electrocautery with ligation of the pedicle as regarding cost, operative time, post-operative bleeding, pain, and healing process.

\section{Patients and Methods}

Study design: The present study was a prospective randomized trial that was conducted on patients selected from Ain Shams University Hospitals and October 6 University Hospital through the period from January to June 2019.

Fifty consecutive patients were randomly divided equally into two groups: Group I: Harmonic scalpel hemorrhoidectomy without ligation of the pedicle. Group II: Electrocautery with ligation of the pedicle.

Ethical statement: We confirm that the present study run in concordance with international ethical standards and applicable local regulatory guidelines. A written informed consent was obtained from the parents of every eligible patient. Patients were informed about the study objectives, methodology, risk, and benefit. The study's protocol was reviewed and approved by Institutional Review Board (IRB), ethics committee or audit Department of Faculty of Medicine, Ain Shams University Hospitals and October 6 University Hospital.

Inclusion criteria: All patients enrolled in the study period if they were: Adults aged more than 18 years. Grade III internal hemorrhoids with external components or Grade IV disease.

Exclusion criteria: Patients with additional anorectal pathology (fissure of fistula). Neurologic deficits (paraplegia, previous strokes). Patients on narcotic analgesics. Patients with bleeding tendency.

Sample size and sampling: We utilized random sampling technique. A total of 50 patients were determined to be included in the present study.

\section{Pre-operative evaluation:}

All patients underwent: Complete history taking. Complete physical examination (both general and local). Sigmoidoscopic examination. Routine preoperative laboratory tests.

\section{Study's procedures:}

The patients were admitted to the surgery department in the hospital one day before the opera- 
tion to be prepared for the operation. The patient was instructed to do a glycerin enema $12 \mathrm{~h}$ before surgery, and the nurse was instructed to give the patient prophylactic antibiotic before going to the surgical room. The patients were placed in lithotomy position under spinal anesthesia or general anesthesia. Open technique was used in all cases. The anus was exposed by attaching tape to both sides of the buttocks. Situation of hemorrhoids was determined with an anoscope. The technique used for surgical hemorrhoidectomy was standardized in all patients. This was performed with a $27 \mathrm{G}$ needle, using $12 \mathrm{mg}$ of $0.5 \%$ hyperbaric bupivacaine associated with morphine (70 vasoconstrictor was used routinely, apart from ephedrine $(10 \mathrm{mg})$ if blood pressure decreased $20 \%$ from baseline values. A modified Ferguson three quadrant hemorrhoidectomy was performed in all patients.
Harmonic scalpel group: In harmonic scalpel hemorrhoidectomy, excision of hemorrhoids was done with the help of vascular forceps and without damaging the internal anal sphincter. The hemorrhoidal pedicle were coagulated with a harmonic scalpel without ligation of the pedicle.

Electrocautery group: Ligation of the pedicle with 0 polyglycolic acid material after electrocautery and excision was done.

\section{Post-operative care:}

A multiple elongated wrapped gauze was inserted in the anal canal post-operatively to help in hemostasis. Diclofenac potassium, paracetamol, metronidazole, flavonoid, local antibiotics and laxatives were prescribed post-operatively. Patients were discharged from hospital $24 \mathrm{~h}$ after the surgery if they had no complications post-operatively.

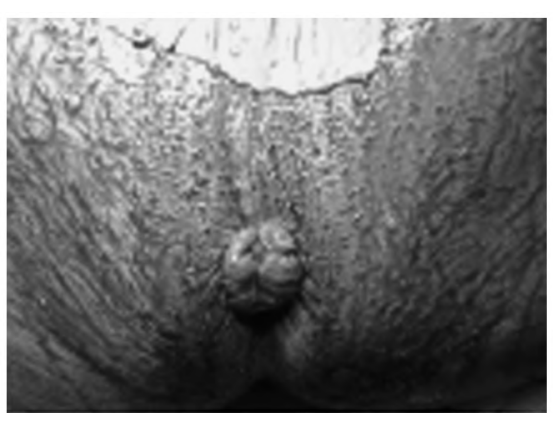

Fig. (1): Grade 4 hemorrhoids before harmonic hemorrhoidectomy.

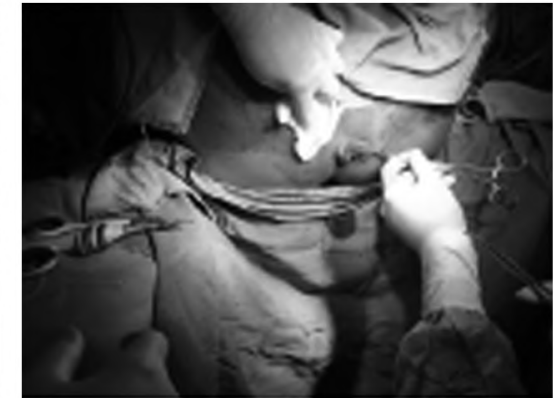

Fig. (2): During the procedure of harmonic hemorrhoidectomy.

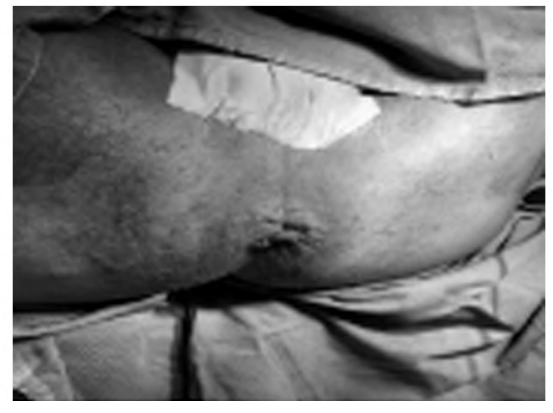

Fig. (3): After excision of mother piles $(3,7,11)$ using harmonic scalpel.

\section{Follow-up and study's outcomes:}

Scores of pain at rest and after defecation were recorded on Visual Analog Scale (VAS) from 0 to 10. The patients were evaluated for wound healing, early and late complications such as hemorrhage, retention of urine, anal verge stenosis and fecal incontinence just after the operation and along the period of follow-up. Bleeding was considered major if the patient needed blood transfusion, reoperation, or close observation for the vital signs.

Patients were followed-up on 1, 3, 7, 15 and 30 days after surgery, and the patients were assessed by other assessors who were blind to the type of operation done for the patient.

\section{Statistical analysis:}

An Excel spreadsheet was established for the entry of data. We used validation checks on numerical variables and option-based data entry method for categorical variables to reduce potential errors. The analyses were carried with SPSS software (Statistical Package for the Social Sciences, version 24, SSPS Inc, Chicago, IL, USA). The normality of the data were assessed using ShapiroWilk Test. Numerical data were described as mean \pm SD if normally distributed; or median and Interquartile Range [IQR] if not normally distributed. Frequency tables with percentages were used for categorical variables. Independent Student $t$-test and paired $t$-test were used to compare parametric quantitative variables; while Mann-Whitney tests and Wilcoxon matched pairs test were used to compare non-parametric quantitative variables. Chi-square test or McNemar-Bowker tests were used to analyze categorical variables. Multilinear logistic regression was undertaken to assess the predictors of mortality. A $p$-value $<0.05$ is considered statistically significant.

\section{Results}

Table (2) shows the association between type of procedure and operative characteristics. There was statistically significant association between type of procedure and operative time $(p=0.002)$. Patients who underwent Harmonic scalpel hemor- 
rhoidectomy had statistically significant shorter operative time. On the contrary, there were no statistically significant associations between type of blood loss $(p=0.32)$ or mode of management of bleeding $(p=0.67)$.

Table (1): The demographic characteristics of the included patients.

\begin{tabular}{llll}
\hline Variables & $\begin{array}{c}\text { Electrocautery } \\
\text { group (N=25) }\end{array}$ & $\begin{array}{c}\text { Harmonic } \\
\text { group (N=25) }\end{array}$ & $\begin{array}{c}p \text { - } \\
\text { value }\end{array}$ \\
\hline Age in years: & & & \\
Mean \pm SD & $40.04 \pm 11.9$ & $39.96 \pm 11.4$ & 0.98 \\
Median (range) & $38(20-61)$ & $40(21-60)$ & \\
Gender, No. (\%): & & & \\
Male & $15(60 \%)$ & $12(48 \%)$ & 0.32 \\
Female & $10(40 \%)$ & $13(52 \%)$ & \\
Medical history: & & & \\
Asthma & $1(4 \%)$ & $1(4 \%)$ & 0.45 \\
DM & $2(8 \%)$ & $5(20 \%)$ & \\
HTN & $1(4 \%)$ & 0 & \\
DM, HTN & $2(8 \%)$ & $2(8 \%)$ & \\
IHD & $2(8 \%)$ & 0 & \\
DM. HTN, IHD & 0 & $2(8 \%)$ & \\
\hline
\end{tabular}

*Data are presented as mean $\pm \mathrm{SD}$, median (Range), or number $(\%)$.

Table (2): Operative characteristics of the included patients.

\begin{tabular}{|c|c|c|c|}
\hline Variables & $\begin{array}{l}\text { Electrocautery } \\
\text { group }(\mathrm{N}=25)\end{array}$ & $\begin{array}{c}\text { Harmonic } \\
\text { group }(\mathrm{N}=25)\end{array}$ & $\begin{array}{c}p- \\
\text { value }\end{array}$ \\
\hline \multicolumn{4}{|c|}{ Operative time in min: } \\
\hline Mean \pm SD & $25.6 \pm 3.2$ & $16.96 \pm 12.1$ & \multirow[t]{2}{*}{0.001} \\
\hline Median (range) & $25(20-30)$ & $17(14-20)$ & \\
\hline \multicolumn{4}{|l|}{ Blood loss in $m L$ : } \\
\hline No & $19(76 \%)$ & $22(88 \%)$ & \multirow[t]{3}{*}{0.32} \\
\hline Minor & $5(20 \%)$ & $2(8 \%)$ & \\
\hline Major & $1(4 \%)$ & $1(4 \%)$ & \\
\hline \multirow{2}{*}{\multicolumn{4}{|c|}{$\begin{array}{l}\text { Management of } \\
\text { Blood loss: }\end{array}$}} \\
\hline & & & \\
\hline Vit K, packing & $3(12 \%)$ & $1(4 \%)$ & \multirow[t]{3}{*}{0.67} \\
\hline Conservative & $2(8 \%)$ & $1(4 \%)$ & \\
\hline Operative & $1(4 \%)$ & $1(4 \%)$ & \\
\hline
\end{tabular}

*Data are presented as mean $\pm \mathrm{SD}$, median (Range), or number $(\%)$.

Table (3) shows the association between type of procedure and pain scores. There was statistically significant association between type of procedure and operative time ( $p=0.001)$. Patients who underwent Harmonic scalpel hemorrhoidectomy had statistically significant lower pain score at day 1 , $3,7,15$, and 30 .

Table (4) shows the association between type of procedure and post-operative outcomes. There was statistically significant association between type of procedure and time to heal $(p=0.001)$. Patients who underwent Harmonic scalpel hemorrhoidectomy had statistically significant shorter time to complete healing. On the contrary, there was statistically significant association between type of procedure and hospital stay $(p=0.18)$.

Table (3): Association between type of procedure and pain.

\begin{tabular}{llll}
\hline Variables & $\begin{array}{c}\text { Electrocautery } \\
\text { group }(\mathrm{N}=25)\end{array}$ & $\begin{array}{c}\text { Harmonic } \\
\text { group }(\mathrm{N}=25)\end{array}$ & $\begin{array}{c}p \text { - } \\
\text { value }\end{array}$ \\
\hline VAS at days 1: & & & \\
$\quad$ Mean \pm SD & $7.64 \pm 0.81$ & $6.2 \pm 0.76$ & 0.001 \\
Median (range) & $8(6-9)$ & $6(5-7)$ & \\
VAS at days 3: & & & \\
Mean \pm SD & $7.44 \pm 0.96$ & $5.88 \pm 0.67$ & 0.001 \\
Median (range) & $7(5-9)$ & $6(5-7)$ & \\
VAS at days 7: & & & \\
Mean \pm SD & $6.56 \pm 1.1$ & $4.56 \pm 0.58$ & 0.001 \\
Median (range) & $6(4-8)$ & $5(4-6)$ & \\
VAS at days 15: & & & \\
Mean \pm SD & $4.84 \pm 1.1$ & $2.76 \pm 0.59$ & 0.001 \\
Median (range) & $5(3-7)$ & $3(2-4)$ & \\
VAS at days 30: & & & \\
Mean \pm SD & $2.64 \pm 0.95$ & $0.64 \pm 0.55$ & 0.001 \\
Median (range) & $2(1-5)$ & $1(0-2)$ & \\
\hline
\end{tabular}

*Data are presented as mean $\pm \mathrm{SD}$, median (Range).

Table (4): Association between type of procedure and postoperative outcomes.

\begin{tabular}{llll}
\hline Variables & $\begin{array}{c}\text { Electrocautery } \\
\text { group }(\mathrm{N}=25)\end{array}$ & $\begin{array}{c}\text { Harmonic } \\
\text { group }(\mathrm{N}=25)\end{array}$ & $\begin{array}{c}p \text { - } \\
\text { value }\end{array}$ \\
\hline Time to Heal in weeks: & & & \\
Mean \pm SD & $8.52 \pm 2.2$ & $5 \pm 0.86$ & 0.001 \\
Median (range) & $8(5-12)$ & $5(4-6)$ & \\
Hospital stay in hours: & & & \\
Mean \pm SD & $1.24 \pm 0.43$ & $1.08 \pm 0.4$ & 0.018 \\
Median (range) & $1(1-2)$ & $1(1-3)$ & \\
\hline
\end{tabular}

*Data are presented as mean \pm SD and median (Range).

Table (5) shows the association between type of procedure and late complications. There was statistically significant association between type of procedure and late complications $(p=0.001)$. Patients who underwent Harmonic scalpel hemorrhoidectomy had statistically significant less incidence of late complications.

Table (5): Late complications of the included patients.

\begin{tabular}{llll}
\hline Variables & $\begin{array}{c}\text { Electrocautery } \\
\text { group }(\mathrm{N}=25)\end{array}$ & $\begin{array}{c}\text { Harmonic } \\
\text { group }(\mathrm{N}=25)\end{array}$ & $\begin{array}{c}p \text { - } \\
\text { value }\end{array}$ \\
\hline $\begin{array}{llll}\text { Post-operative } \\
\text { complications, No (\%): }\end{array}$ & & & \\
No & $20(80 \%)$ & $23(92 \%)$ & 0.001 \\
Anal stenosis & $3(12 \%)$ & $1(4 \%)$ & \\
Recurrence & $2(8 \%)$ & $1(4 \%)$ & \\
\hline
\end{tabular}

*Data are presented as mean $\pm \mathrm{SD}$, median (range), or number $(\%)$. 


\section{Discussion}

Hemorrhoidal disease is a very prevalent disorder that arises from engorgement of internal and/or external vascular plexuses surrounding the anal canal. The fundamental symptoms are bleeding, pain, prolapsing, and itching. The disease has four grades. Surgical treatment is the first choice in patients with grade III or grade IV hemorrhoids who have symptoms [12]

Hemorrhoidectomy is the standard treatment for grade III or grade IV internal hemorrhoids; in spite of this, pain after conventional hemorrhoidectomy is still a major challenge. Several devices such as harmonic and ligasure scalpels have been developed for reducing intraoperative bleeding, post-operative pain, and post-operative complications such as bleeding, anal incontinence, and anal stenosis [13].

The newly developed surgical equipment such as bipolar-diathermy, harmonic, and ligasure scalpels in addition to circular staplers are recently used in the surgical treatment of hemorrhoids, and the results are good regarding the lesser bleeding and better pain control, which decreased the need for analgesics post-operatively when compared with hemorrhoidectomies performed with the conventional surgical methods. The previous advantages of harmonic scalpel hemorrhoidectomy are owing to better hemostasis and lesser tissue damage.

The harmonic scalpel was used for coagulation and cutting simultaneously and exhibited minimal surrounding thermal spread $(<2 \mathrm{~mm})$ and limited tissue charring which contributed to lower postoperative pain, reduced risk for infection, and faster wound healing. Moreover, the harmonic scalpel exhibited less intraoperative blood loss, better exposure of the operative field, and lesser operative time [14]

The aim of this study was to compare the outcome of hemorrhoidectomy using Harmonic scalpel without ligation of the pedicle versus electrocautery with ligation of the pedicle as regarding cost, operative time, post-operative bleeding, pain, and healing process.

The present study was a prospective, clinical, randomized, trial that included 50 patients grade III internal hemorrhoids with external components or grade IV disease. The patients were divided into two groups: Group I that included 25 patients underwent electrocautery with ligation of the pedicle and Group II which included 25 patients under- went Harmonic scalpel hemorrhoidectomy without ligation of the pedicle.

The mean age of the included patients in group I was $40.04 \pm 11.9$ years and $60 \%$ of patients were males while the mean age of the included patients in group II was $39.96 \pm 11.4$ years and $48 \%$ of patients were males and there were no statistically significant differences between both groups in terms of age $(p=0.98)$, medical history $(p=0.45)$, or gender $(p=0.32)$.

Our study showed that the association between type of procedure and operative characteristics. There was statistically significant association between type of procedure and operation time $(p=0.002)$. Patients who underwent Harmonic scalpel hemorrhoidectomy had statistically significant shorter operative time. On the contrary, there were no statistically significant associations between type of blood loss $(p=0.32)$ or mode of management of bleeding ( $p=0.67$ ).

Ravi et al., [15] in his study showed that the blood loss during the procedure was lesser in harmonic scalpel group $(6.1 \mathrm{ml}$ for harmonic scalpel group vs. 19.4 for Milligan-Morgan group).

As regard the association between type of procedure and pain scores, there was statistically significant association between type of procedure and operative time ( $p=0.001)$. Patients who underwent Harmonic scalpel hemorrhoidectomy had statistically significant lower pain score at day 1 , $3,7,15$, and 30 .

Ravi and his colleagues conducted a study on 60 patients to compare harmonic scalpel hemorrhoidectomy with conventional open method (Milligan-Morgan); they found that the VAS pain scores at days 1,7 , and 14 post-operatively were lesser in harmonic scalpel group compared with MilliganMorgan group [15]

According to the association between type of procedure and post-operative outcomes. There was statistically significant association between type of procedure and time to heal $(p=0.001)$. Patients who underwent Harmonic scalpel hemorrhoidectomy had statistically significant shorter time to complete healing. On the contrary, there was statistically significant association between type of procedure and hospital stay $(p=0.18)$.

Ravi et al., [15] in his study showed postoperative complications such as hemorrhage and urinary retention were more in Milligan-Morgan group. 
For the association between type of procedure and late complications in our study, there was statistically significant association between type of procedure and late complications $(p=0.001)$. Patients who underwent Harmonic scalpel hemorrhoidectomy had statistically significant less incidence of late complications.

Lim et al., [13] conducted a prospective study on 50 patients who had grade III or grade IV internal hemorrhoids. Hemorrhoidectomy operation was done for all patients: 25 by harmonic scalpel and 25 sutured by 3-0 vicryl material after excision (conventional method). The harmonic scalpel group had a shorter procedure time, lesser pain in the post-operative period as assessed by the VAS, and lesser post-operative hemorrhage $(p=0.034)$. The post-operative complications showed no significant variations between the two groups.

Bulus et al., [16] in his study concluded that hemorrhoidectomy done by harmonic scalpel is more safe and effective, has fewer complications, and causes lesser blood loss and lesser postoperative pain when compared with conventional techniques. Their results were significant regarding operative time, mean hospital stay, and postoperative static pain for post-operative days 1,7 , and 28 , respectively. The post-operative complications such as bleeding, anal incontinence, and anal stenosis were lesser in HS hemorrhoidectomy group but without significance.

Talha et al., [17] showed that both harmonic scalpel and ligasure were superior to conventional diathermy in hemorrhoidectomy, in having lesser operative time, lesser post-operative pain, and lesser analgesic consumption during the first day post-operatively in addition to faster wound healing.

Abo-Hashem [18] in his study in 2010 reported a significant fast wound healing in harmonic scalpel hemorrhoidectomy. They attributed this higher rate of wound healing at 6 weeks post-operatively to the minimal tissue trauma, minimal charring, lesser local edema in the surrounding tissues, and absence of tissue necrosis.

Both Ozer and Abo-Hashem in their study concluded that harmonic scalpel hemorrhoidectomy is superior to conventional hemorrhoidectomy regarding significant reduction in postoperative pain scoring, induction of better hemostasis of the wound, and lesser consumption of analgesic $[\mathbf{1 8 , 1 9 ]}$

\section{Conclusion:}

It is concluded that there was significantly reduced post-operative pain after Harmonic Scalpel hemorrhoidectomy compared with electrocautery controls. The diminished post-operative pain in the Harmonic Scalpel group likely results from the avoidance of lateral thermal injury.

\section{References}

1- SUN W.M., PECK R.J., SHORTHOUSE A.J. and READ N.W.: Haemorrhoids are associated not with hypertrophy of the internal anal sphincter, but with hypertension of the anal cushions. Br. J. Surg., 79: 592-4, 1992.

2- NOORCHASHM H. and MARON D.J.: Procedures for Benign Anorectal Disease. InGowned and Gloved Surgery: Introduction to Common Procedures. WB Saunders, pp. 145-56, 2009

3- DAVIS B.R., LEE-KONG S.A., MIGALY J., FEINGOLD D.L. and STEELE S.R.: The American Society of Colon and Rectal Surgeons Clinical Practice Guidelines for the Management of Hemorrhoids. Dis. Colon. Rectum., 61 (3): 284-92, 2018.

4- GIBBONS C.P., BANNISTER J.J. and READ N.W.: Role of constipation and anal hypertonia in the pathogenesis of haemorrhoids. Br. J. Surg., 75 (7): 656-60, 1988.

5- BERNSTEIN W.C.] What are hemorrhoids and what is their relationship to the portal venous system? Dis. Colon. Rectum., 26 (12): 829-34, 1983.

6- WALD A., BHARUCHA A.E., COSMAN B.C., et al.: ACG clinical guideline: Management of benign anorectal disorders. Am. J. Gastroenterol., 109 (8): 1141-57; (Quiz) 1058, 2014.

7- MILLIGAN E.T., MORGAN C.N., JONES L.E. and OFFICE R.: Surgical anatomy of the anal canal, and the operative treatment of hæmorrhoids. Lancet, 230: 111924, 1937.

8- FERGUSON J.A. and HEATON J.R.: Closed hemorrhoidectomy. Dis. Colon. Rectum., 2 (2): 176-9, 1959.

9- ARMSTRONG D.N., AMBROZE W.L., SCHERTZER M.E. and ORANGIO G.R.: Harmonic scalpel ${ }^{\circledR}$ vs. electrocautery hemorrhoidectomy: A prospective evaluation. Dis. Colon. Rectum., 44 (4): 558-64, 2001.

10- McCARUS S.D.: Mechanism of ultrasonically activated scalpel. J. Am. Assoc. Gynecol. Laparosc., 3: 601-8, 1996.

11-LEFF E.I.: Hemorrhoidectomy-laser vs. non laser: Outpatient surgical experience. Dis. Colon. Rectum., 35: 7436, 1992.

12- MEGAHED H.A.: Harmonic scalpel versus conventional hemorrhoidectomy. Al-Azhar Assiut Med. J., 17: 24-9, 2019.

13- LIM D.R., CHO D.H., LEE J.H. and MOON J.H.: Comparison of a hemorrhoidectomy with ultrasonic scalpel versus a conventional hemorrhoidectomy. Ann. Coloproctol., 32: 111-6, 2016.

14- DEVASSY R., HANIF S., KRENTEL H., VERHOEVEN H.C., La ROCHE L.A.T., De WILDE R.L.: Laparoscopic ultrasonic dissectors: Technology update by a review of literature. Med. Devices. (Auckl), 12: 1-7, 2018.

15-RAVI KUMAR G.V., MADHU B.S., VISHAL T., NAVIN KUMAR REDDY M. and PAWAR P.M.: Harmonic scalpel compared with conventional open (Milligan-Morgan) 
method in surgical management of symptomatic haemorrhoids. Int. Surg. J., 4: 2010-3, 2017.

16- BULUS H., TAS A., COSKUN A. and KUCUKAZMAN M.: Evaluation of two hemorrhoidectomy techniques: Harmonic scalpel ${ }^{\circledR}$ and Ferguson's with electrocautery. Asian J. Surg., 37: 20-3, 2014.

17-TALHA A., BESSA S. and ABDEL WAHAB M.: Ligasure, harmonic scalpel versus conventional diathermy in exci- sional haemorrhoidectomy: A randomized controlled trial. ANZ J. Surg., 87: 252-6, 2017.

18- ABO-HASHEM A.A., SARHAN A. and ALY A.M.: Harmonic scalpel compared with bipolar electro-cautery hemorrhoidectomy: A randomized controlled trial. Int. J. Surg., 8: 243-7, 2010.

19- OZER M.T., YIGIT T., UZAR A.I., MENTES O., HARLAK A., KILIC S., et al.: A comparison of different hemorrhoidectomy procedures. Saudi Med. J., 29: 1264-9, 2008.

\section{دراسة مقارنة بين إستئصال البواسير بالمشرط التوافقى والمشرط الكهريائى}

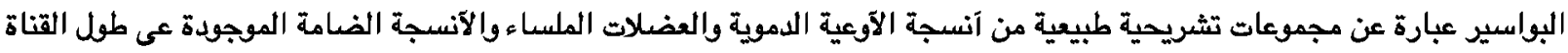

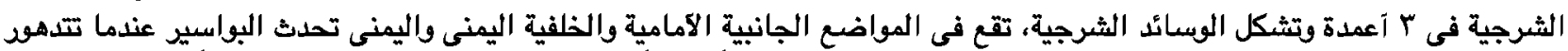

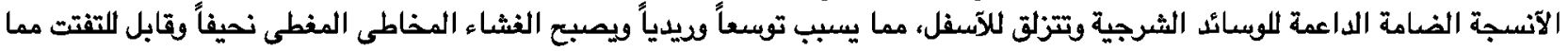

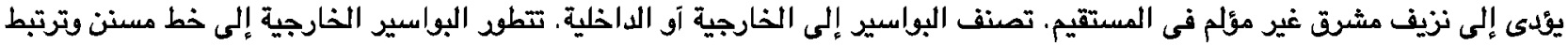
عادة بالالم بينما تتطود البواسير الداخلية القريبة من خط المئن فئن وتكن عادة غير مؤلمة.

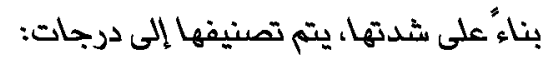

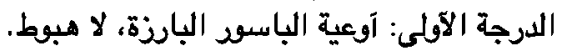

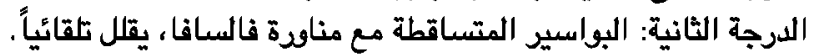

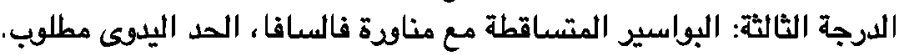
الدرجة الرابع: البواسير المزمنة، الدداليدوى غير فعال.

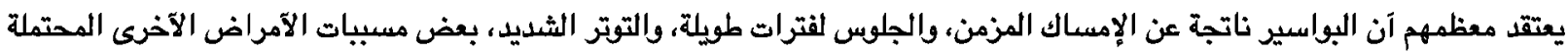

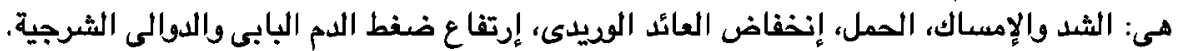

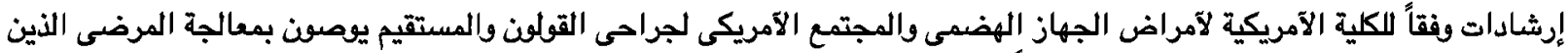

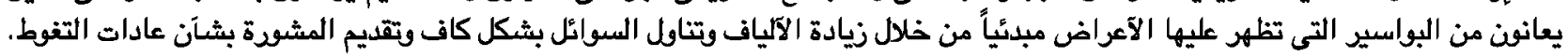

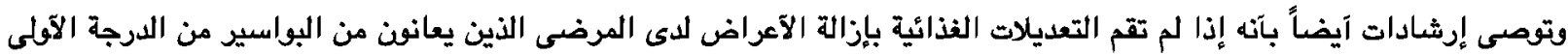

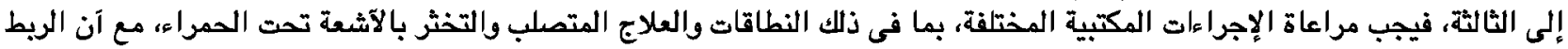
ريما يكن العلاج الآكثر فعالية.

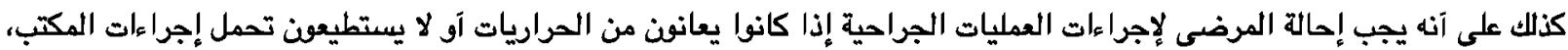

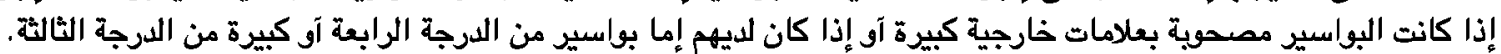

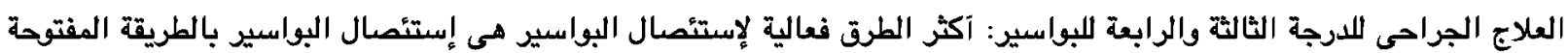

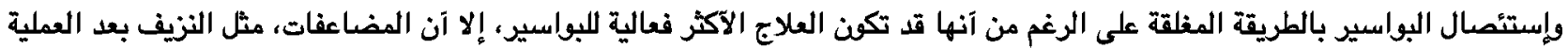

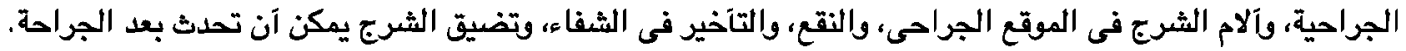

نتيجة لذالك، تم تقديم العديد من المعدات الجراحية والأساليب الجراحية والعلاجات الداعمة للتظلب على مضاعفات ما بعد الجراحة.

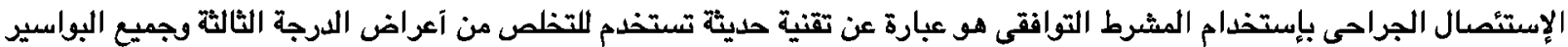

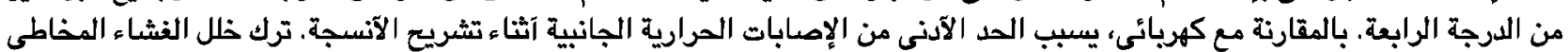
الناتج فى هذه الدراسة مفتوحاً.

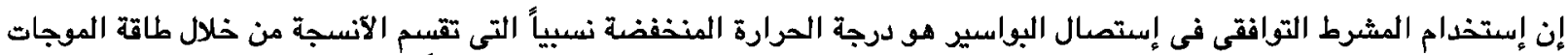

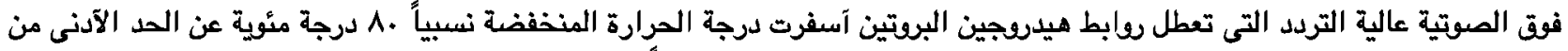

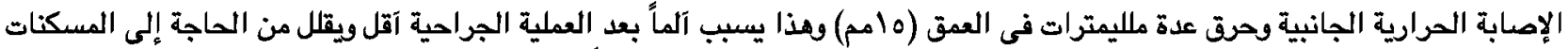

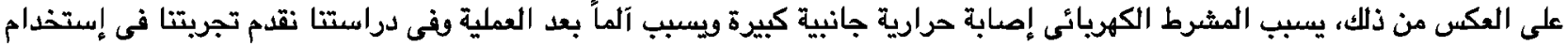
مشرط التوافقى فى إستئكال البواسير وتقييم مضاعفات ما بعد الجراحة مقارنة بإستخدام المشرط الكهريائى. 